\title{
BMJ Open Determinants of knowledge of critical danger signs, safe childbirth and immediate newborn care practices among auxiliary midwives: a cross sectional survey in Myanmar
}

\author{
Kyu Kyu Than, ${ }^{1,2}$ Alison Morgan, ${ }^{3}$ Minh Duc Pham,, ${ }^{1,4}$ James G Beeson, ${ }^{1,2}$ \\ Stanley Luchters ${ }^{1,4,5}$
}

To cite: Than KK, Morgan A, Pham MD, et al. Determinants of knowledge of critical danger signs, safe childbirth and immediate newborn care practices among auxiliary midwives: a cross sectional survey in Myanmar. BMJ Open 2017;7:e017180. doi:10.1136/ bmjopen-2017-017180

- Prepublication history for this paper is available online. To view these files please visit the journal online (http://dx.do org/10.1136/bmjopen-2017017180).

Received 6 April 2017 Revised 15 May 2017 Accepted 22 May 2017

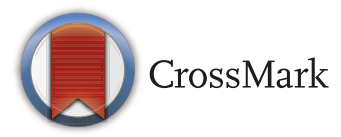

For numbered affiliations see end of article.

Correspondence to

Proffesor Stanley Luchters:

stanley.luchters@burnet.edu.au

\section{ABSTRACT}

Objectives The re-emergence of community-based health workers such as the auxiliary midwives (AMWs) in Myanmar, who are local female volunteers, has been an important strategy to address global health workforce shortages. The Myanmar government recommends one AMW for every village. The aim of this study is to investigate the current knowledge of critical danger signs and practices for safe childbirth and immediate newborn care of AMWs to inform potential task shifting of additional healthcare responsibilities.

Methods A cross-sectional survey was conducted from July 2015 to June 2016 in three hard-to-reach areas in Myanmar. Face-to-face interviews were conducted using a pretested questionnaire.

Results Among 262 AMWs participating in the study, only $8 \%$ of AMWs were able to identify at least $80 \%$ of 20 critical danger signs. Factors associated with greater knowledge of critical danger signs included older age over 35 years (adjusted OR (AOR) 2.19, 95\% Cl 0.99 to 4.83 ), having received refresher training within the last year (AOR 2.20, 95\% Cl 1.21 to 4.01) and receiving adequate supervision (AOR 5.04, 95\% Cl 2.74 to 9.29). Those who employed all six safe childbirth and immediate newborn care practices were more likely to report greater knowledge of danger signs (AOR 2.81, 95\% $\mathrm{Cl} 1.50$ to 5.26), adequate work supervision (AOR $3.1895 \% \mathrm{Cl} 1.62$ to 6.24 ) and less education (AOR $0.44,95 \% \mathrm{Cl} 0.23$ to $0.88)$.

Conclusion The low level of knowledge of critical danger signs and reported practices for safe childbirth identified suggest that an evaluation of the current AMW training and supervision programme needs to be revisited to ensure that existing practices, including recognition of danger signs, meet quality care standards before new interventions are introduced or new responsibilities given to AMWs.

\section{INTRODUCTION}

The re-emergence of the role of community health workers (CHWs) in healthcare provision has been an asset to the global health
Strengths and limitations of this study

- The study presents valuable information on the current knowledge of critical danger signs and practices for safe childbirth and immediate newborn care of auxiliary midwives (AMWs) in Myanmar.

- Practices of AMWs were based on self-reported practices rather than actual observed performance, and over-reporting can be a problem with this approach. Moreover, composite variables were created for analysis, which could have led to misclassification bias.

- Low level of knowledge of critical danger signs and reported practices for childbirth suggest that an evaluation of the current AMW training and supervision programme needs to be revisited to ensure that existing practices, including recognition of danger signs, meet quality care standards.

workforce. ${ }^{1}$ Around the world, different types of CHWs have emerged that are adapted to the need of individual healthcare systems and country contexts. ${ }^{2}$ CHWs are defined as 'community members who work almost exclusively in community settings and who serve as connectors between healthcare consumers and providers to promote health among groups that have traditionally lacked access to adequate care'. ${ }^{3}$ Most CHWs working in maternal and child health are women.

Auxiliary midwives (AMWs) are one of the largest voluntary health cadres in the country and have been trained by the government of Myanmar since $1978 .{ }^{4}$ They are local women with secondary level education who are willing to serve their own community with maternal and child healthcare service and who work without financial incentives. The aim of producing AMWs in the early years of the programme was twofold: to fill the gap in 
the availability of skilled birth attendants (midwives) who were not accessible in remote rural villages of the country and to phase out traditional birth attendants as care providers. AMWs provide education and counselling to pregnant women on antenatal care, immunisation, nutrition, birth preparedness, breast feeding and postnatal care. They are also equipped with skills to conduct normal deliveries, identify pregnant women with greater risks of complication and facilitate early and timely referral. ${ }^{45}$

Myanmar has a critical shortage in human resources for health; there are only 14 health providers with midwifery skills (doctors, nurses and midwives) per 10000 persons. This is significantly less than 23 per 10000 persons recommended by the WHO to achieve the $80 \%$ skilled coverage for maternal and child health. ${ }^{6}$ Although the Myanmar government recognises the need to increase the number of skilled birth attendants and the distribution of midwives, health system resources are lacking and policies to fill and sustain the human resource gap are not currently in place. ${ }^{7}$ Task shifting is one possible option to address human resource shortages, and the Ministry of Health has revitalised the AMW programme to help extend services to 'hard-to-reach' areas. ${ }^{8}$ The national target set by the Ministry is to have at least one trained AMW in every village by $2016 .^{7}$ The Ministry also recommends task shifting evidence-based essential interventions to AMWs to improve the health of mothers and the newborns. ${ }^{9}$

Currently, AMWs' training lasts for 6 months, including 3 months of theoretical learning and 3 months of practical skills provided by township health departments. The trainings are conducted under the guidance of the Ministry of Health. ${ }^{7}$ Within the current 'Three Millennium Development Goals Fund' (3MDG) for Magwe region, new and refresher trainings have been undertaken in Gangaw, Ngape and Seitphyu townships. Refresher trainings are provided by the township-level team, which consists of the township medical officer, township health nurse and other health staff within each township and entails 3-5 days covering the critical topics relevant to AMW practice. AMWs are supervised by the midwives in their township. ${ }^{10}$ Typically, a midwife is responsible for overseeing four to six AMWs and would visit each AMW every month to monitor performance. In practice, it is reported that many midwives are not able to regularly follow-up the AMWs for whom they are responsible. ${ }^{11}$

Although the number of AMWs has increased, there are few studies on AMW service provision and performance in Myanmar. Two studies conducted by the Department of Health in 2005 and 2011 reported that knowledge was low and that AMW skills were below satisfactory level. The first study included 211 AMWs from 12 townships and the second study included 287 AMWs from four townships. ${ }^{12} 13$ These studies assessed AMWs' general maternal and child health knowledge and skills but did not focus on the critical danger signs.

Our study aimed to investigate the level of knowledge and practices specific to life-saving care for pregnant women and their newborns: recognition of critical danger signs during pregnancy and labour, clean and safe childbirth practices and immediate newborn care practices. In addition, we examined the determinants of knowledge level to inform future interventions needed to improve the care given by AMWs in Myanmar.

\section{METHODS}

\section{Study setting}

Myanmar is a country with geographically, culturally and socially diverse communities. Magwe region in central Myanmar and with a population of 3.9 million was purposively selected based on its high reported maternal mortality ratio (344 per 100000 live births) and infant mortality rate (84 per 1000 live births). ${ }^{15}$ The region contains various hard-to-reach populations and in rural remote areas most of the birth takes place at home (nationally reported to be $72 \%$ ). ${ }^{16}$ Within each township, villages were identified as hard-to-reach and non-hard-to-reach according to the 3MDG fund criteria (a score of $0-12$ is accorded based on travelling time to the nearest facility, mode of travel, transport charges and roads affected by seasonal variation). ${ }^{17}$ Three townships in Magwe region (Gangaw, Ngape and Seitphyu) were purposively selected to represent the geographical diversity of the region and because they have high maternal and infant mortality.

\section{Study design and participants}

A cross-sectional survey using interviewer administered pretested questionnaire was conducted between July 2015 and June 2016. A list of practising AMWs was obtained from the township health departments and checked through discussions with the township medical officer. All practising AMWs in the three townships were recruited for interviews. AMWs who were not in the township and those who could not come to the rural health centre (RHC) due to bad weather or having a very young child at the time of the survey were not able to participate. A total of 262 AMWs participated in the study out of 308 invited to participate $(85 \%)$.

\section{Data collection methods}

Data were collected using a pretested semistructured questionnaire in Myanmar language. Five trained interviewers conducted face-to-face interviews with AMWs after obtaining written, informed consent. Interviewers were not employed by or associated with the health system. Completing the questionnaire took approximately $30-45 \mathrm{~min}$ per interview. The questionnaire consisted of five main sections including socioeconomic and demographic characteristics, training and supervision of maternal and child health services, knowledge of risk and danger signs, practice of antenatal, birth, postnatal and newborn care and barriers and facilitators for provision of services. In order to reduce the recall bias, all the knowledge and practice questions were based on 6 months period before the data collection. Interviews were conducted in the closest Maternal and Child Health 
Centre or RHC to each AMWs' place of residence. All the participants were reimbursed with the actual cost of travel to the place of interview plus a daily allowance to cover meal costs (3000 kyats, equivalent to US\$2.5).

\section{Data management and analysis}

Data were coded on the day of the interview by a different member of the research team to check for incompleteness and inconsistency. There were no missing data. Coded data were double entered into the software Epi Data V.3.1 by two research assistants separately. Double data entry was then checked for consistency by the principal investigator and any discrepancies addressed through discussion with the research team. The principal investigator analysed the data using STATA V.13.1.

Binary and categorical variables were summarised by proportions and tabulations. Continuous variables were summarised using mean, SD and range. Differences between groups were assessed using $\chi^{2}$ tests and/ or univariable logistic regression with $95 \%$ CI. The effect of each of the independent variables was adjusted for all other independent variables in a multivariable logistic regression model. Variables were included in the model if they were known, or hypothesised, determinants of our outcomes of interest.

\section{Study measures}

Responses to the question "when was the last refresher training received' was coded as 'less than a year' if the participant indicated training had been received more recently than 2014 and as "no training or more than 1 year' if refresher training had not been received or received prior to 2014. The number of supervision visits in the last 6 months and the question on satisfaction of supervision were taken to create the adequate supervision variable as reported by AMWs in the study. The question on 'how many times were you supervised in the last 6 months' was categorised as 'less than six times or no supervision received' and 'six times and more'. Another question explored their satisfaction with the received supervision and was asked as: 'Are you satisfied with your supervision?' Responses were re-categorised into a binary variable as 'satisfied' for responses 'very satisfied', 'satisfied' and 'just satisfied' and into 'not satisfied' when responses included 'not very satisfied 'and 'not satisfied at all'. A composite variable was constructed to describe the adequacy of supervision. If the number of supervisions was six times and more in the last 6 months and the satisfaction question was categorised as satisfied, it was considered as 'adequate supervision' and if either the number of supervision was no or less than six times or the satisfaction question was categorised as not satisfied than it was considered as 'not adequate.'

According to the latest AMW manual published in 2015, there are 20 critical danger signs: six in pregnancy, eight in childbirth and postpartum and six related to newborn care. Knowing critical danger signs is important to enable AMWs to refer mothers and newborns for timely and effective management of complications. Participants were coded as 'high knowledge' if they reported at least three pregnancy critical danger signs (out of six), four childbirth and postpartum critical danger signs (out of eight) and three newborn critical danger signs (out of six). All others participants were coded as 'low knowledge'.

A safe childbirth practice variable was constructed using responses to questions on usage of a clean birth kit and postpartum haemorrhage prevention practices. The question 'Do you normally use a clean birth kit' was coded as ' 1 ' for yes and ' 0 ' for no. Frequency of Active Management of Third Stage of Labour (AMTSL) practices were coded into a binary variable grouping those who responded 'always', 'mostly' or 'about half the time' as ' 1 ' and those who responded 'sometimes' or 'rarely' as ' 0 '. A composite 'safe childbirth practice' score was then constructed by adding the value of these two variables (using a clean birth kit and practising AMTSL). A score of '2' was considered 'safe childbirth practice' and scores of ' 0 ' or ' 1 ' was considered 'not safe childbirth practice'. AMWs were also asked about the use of misoprostol, an intervention introduced to AMW practice in the study townships in 2015 by the Ministry of Health.

Four immediate newborn care practice questions were given a score of 1 for 'yes' responses and 0 for 'no' responses. Practices assessed were wrapping the baby for warmth, immediate breast feeding after birth, clean cord care and wiping the newborns nose and mouth with a clean cloth or gauze. AMWs who reported all four immediate newborn care practices were categorised as providing 'satisfactory newborn practices', while all others were categorised as 'not satisfactory'. AMWs categorised as providing both safe childbirth practices and satisfactory immediate newborn practices were described as providing 'safe childbirth and immediate newborn care practice'.

\section{Ethical considerations}

Ethical approval for the study was obtained from the Ethics Review Committee of Department of Medical Research, Ministry of Health Myanmar (approval number 42A/ethics/DMR/2015). Ethical approval was also obtained from The Alfred Hospital Human Research Ethics Committee in Australia (approval number Project $150 / 15)$. Written information was provided in Burmese and written inform consent was obtained. Consent forms were stored in a secure location. All activities and procedures including those for data collection, data storage and data analysis were performed in accordance with the guidelines and regulations as stated in the study protocol.

\section{RESULTS}

\section{Characteristics of participants}

A total of 214 AMWs from the non-hard-to-reach villages and 48 AMWs from hard-to-reach villages participated in the survey (table 1). The majority (82\%) of AMWs lived in the villages where they were born (native village) and 
Table 1 Sociodemographic characteristics of participating auxiliary midwives (AMWs)

\begin{tabular}{|c|c|c|}
\hline Variables & $n(n=262)$ & Per cent \\
\hline \multicolumn{3}{|l|}{ Townships } \\
\hline Gangaw & 67 & 25.5 \\
\hline Ngape & 86 & 32.8 \\
\hline Seitphyu & 109 & 41.6 \\
\hline \multicolumn{3}{|l|}{ Villages } \\
\hline Hard-to-reach & 48 & 18.3 \\
\hline Non-hard-to-reach & 214 & 81.7 \\
\hline \multicolumn{3}{|l|}{ Age } \\
\hline$\leq 24$ years & 69 & 26.3 \\
\hline 25-34 years & 105 & 40.1 \\
\hline $35-44$ years & 52 & 19.9 \\
\hline$\geq 45$ years & 36 & 13.7 \\
\hline \multicolumn{3}{|l|}{ Education } \\
\hline Primary & 26 & 9.9 \\
\hline Secondary & 83 & 31.7 \\
\hline High School & 110 & 42.0 \\
\hline University/Graduate & 43 & 16.4 \\
\hline \multicolumn{3}{|l|}{ Marital status } \\
\hline Single & 132 & 50.4 \\
\hline Married & 130 & 49.6 \\
\hline \multicolumn{3}{|c|}{ Number of years lived in the village } \\
\hline$\leq 10$ years & 15 & 5.7 \\
\hline 11-20years & 33 & 12.6 \\
\hline$\geq 21$ years & 214 & 81.7 \\
\hline \multicolumn{3}{|c|}{ Number of years working as an AMW } \\
\hline$\leq 1$ year & 23 & 8.8 \\
\hline $2-5$ years & 89 & 34.0 \\
\hline $6-9$ years & 22 & 8.4 \\
\hline$\geq 10$ years & 128 & 48.9 \\
\hline \multicolumn{3}{|c|}{ Any other job apart from AMW work } \\
\hline AMW only & 148 & 56.5 \\
\hline Manual labour & 8 & 3.1 \\
\hline Farmers & 64 & 24.4 \\
\hline Small business owners & 37 & 14.1 \\
\hline Others & 5 & 1.9 \\
\hline
\end{tabular}

$49 \%$ had worked as AMWs for 10 years or more. The mean age of AMWs was 32 years, and $42 \%$ had secondary and below education and $16 \%$ had university level of education. Forty-five per cent of AMWs in the study worked in other jobs in addition to being an AMW.

\section{Supervision and training}

All AMWs in the study were trained for 6 months within their respective townships. More than half $(57 \%)$ had been trained before 2010 and $64 \%$ of the AMWs reported receiving some refresher training (table 2). Among those
Table 2 Training and supervision received by participating auxiliary midwives (AMWs)

\begin{tabular}{|c|c|c|}
\hline Variables & $n(n=262)$ & Per cent \\
\hline \multicolumn{3}{|c|}{ Year of first AMW training received } \\
\hline 1978-1999 & 75 & 28.6 \\
\hline 2000-2009 & 75 & 28.6 \\
\hline 2010-2015 & 112 & 42.8 \\
\hline \multicolumn{3}{|c|}{ Ever received refresher training } \\
\hline Yes & 169 & 64.5 \\
\hline No & 93 & 35.5 \\
\hline \multicolumn{3}{|c|}{ Refresher training within 1 year } \\
\hline No refresher training & 93 & 35.5 \\
\hline One year and more & 32 & 12.2 \\
\hline Less than 1 year & 137 & 52.3 \\
\hline \multicolumn{3}{|c|}{ Number of supervision received within 6 months } \\
\hline Less than six times & 77 & 29.4 \\
\hline Six times and more & 185 & 70.6 \\
\hline \multicolumn{3}{|c|}{ Reported satisfaction of supervision } \\
\hline Not satisfied & 74 & 28.2 \\
\hline Satisfied & 188 & 71.8 \\
\hline \multicolumn{3}{|l|}{ Adequate supervision* } \\
\hline Not adequate & 124 & 47.3 \\
\hline Adequate & 138 & 52.7 \\
\hline
\end{tabular}

${ }^{*}$ Adequate supervision was defined as receiving supervision six times or more within the last 6 months and was satisfied with the supervision received.

who had received refresher training, $80 \%$ received the refresher training only in 2015 . Seventy per cent reported receiving supervision from a midwife six or more times within the last 6 months and $60 \%$ of these AMWs reported that this supervision was satisfactory.

\section{Knowledge of critical danger signs}

Nearly all AMWs (91\%) knew the recommendation of four antenatal visits with a skilled attendant during pregnancy and $96 \%$ knew the recommendation of three postnatal visits within 14 days of birth. Regarding critical danger signs, AMWs were more knowledgeable about newborn $(77 \%)$ compared with antenatal $(58 \%)$ and birth and postnatal critical danger signs (54\%) (table 3). During the antenatal period, vaginal bleeding, convulsions/fits and severe headache with blurred vision were the most frequently reported critical danger signs. During childbirth and postpartum, the most commonly reported danger signs were bleeding, placenta not expelled 1 hour after birth of the baby and convulsions/fits. Severe abdominal pain, fast and difficult breathing, fever and too weak to get out of bed were the least reported. Although knowing all 20 critical danger signs is an expected AMW competency, only $8 \%$ of participants knew $80 \%$ or more of these danger signs and only $34 \%$ of participants knew at least half of the critical danger signs in each category. 
Table 3 Knowledge of critical danger signs ${ }^{\star}$ for pregnancy, birth, postpartum and newborn care among participating auxiliary midwives (AMWs)

\begin{tabular}{|c|c|c|}
\hline Knowledge of critical danger signs & $n(n=262)$ & Per cent \\
\hline \multicolumn{3}{|l|}{ Pregnancy (six items) } \\
\hline Vaginal bleeding & 214 & 81.6 \\
\hline Severe headache with blurred vision & 152 & 58.0 \\
\hline Fever and too weak to get out of bed & 134 & 51.2 \\
\hline Fast and difficult breathing & 63 & 24.1 \\
\hline Knowing three or more critical danger signs during pregnancy & 151 & 57.6 \\
\hline \multicolumn{3}{|l|}{ Childbirth and postpartum (eight items) } \\
\hline Not in labour within 6 hours of water breaking & 141 & 53.8 \\
\hline Placenta not expelled 1 hour after the birth of the baby (retained placenta) & 152 & 58.0 \\
\hline Convulsion/fits & 156 & 59.5 \\
\hline Fast and difficulty breathing & 51 & 19.5 \\
\hline Fever and too weak to get out of bed & 52 & 19.9 \\
\hline Knowing four or more critical danger signs during birth and postpartum & 142 & 54.2 \\
\hline \multicolumn{3}{|l|}{ Newborn (six items) } \\
\hline Difficult breathing (over $60 / \mathrm{min}$ or less than $30 / \mathrm{min}$ ) & 183 & 69.9 \\
\hline Fits or convulsions & 156 & 59.5 \\
\hline Fever & 161 & 61.5 \\
\hline
\end{tabular}

${ }^{*}$ As defined in the 2015 Myanmar AMW manual.

\section{Safe childbirth and immediate newborn care practices}

The main tasks of AMWs are to perform normal deliveries and to identify and refer high-risk pregnancies and women and newborn showing danger signs to the nearest health facility. On average, AMWs in this study provided antenatal services to four pregnant women, childbirth services to two women and postnatal services to four women in the past 6 months. Although labour monitoring using partograph was included in the AMW manual and is widely recommended as an important tool for the management of labour, only one respondent answered 'yes' to ever using a partograph. In this study, $84 \%$ of AMWs reported normally using a clean birth kit (table 4). Eighty two per cent of AMWs self-reported of conducting AMTSL. However, only $41 \%$ of AMWs reported providing misoprostol after birth to prevent postpartum haemorrhage. Among those who used misoprostol, $75 \%$ used two tablets and $25 \%$ used only one tablet (compared with the recommended three tablet dosage). Only $31 \%$ of AMWs followed all four immediate newborn care practices for a normal birth. All six practices of safe childbirth and immediate newborn care were conducted by only 74 (28\%) of AMWs in the study (table 4).

\section{Determinants of high knowledge of critical danger signs}

Using multiple logistic regression analysis and after adjusting for confounders, variables that were strongly associated with high knowledge of critical danger signs were age 35 years and over, receiving refresher training within 1 year and adequate supervision. AMWs that are older (35 years and over) were 2.19 times more likely to have higher knowledge of critical danger signs compared with AMWs aged less than 35 years $(\mathrm{p}=0.054)$. AMWs who had received refresher training within 1 year were 2.20 times more likely to have better knowledge of the critical danger signs than those who 
Table 4 Proportion of auxiliary midwives (AMWs) reporting specified childbirth and newborn care practices

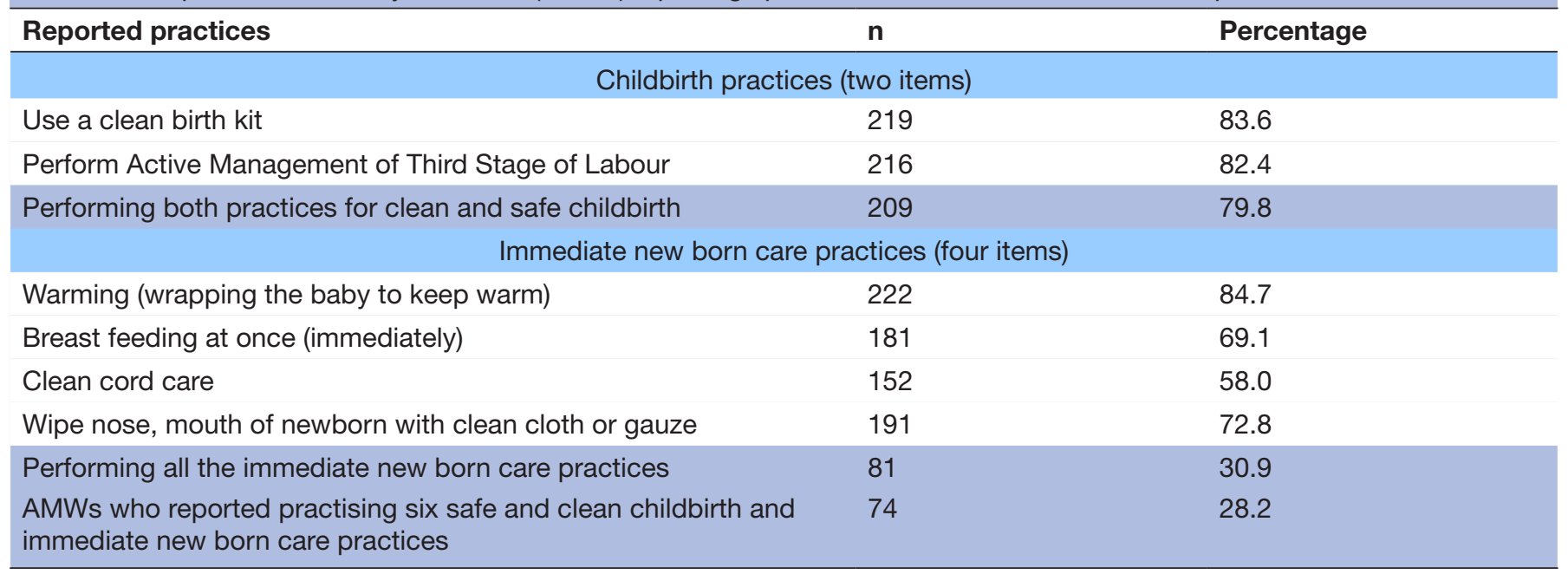

had received no training within the previous year $(\mathrm{p}=0.010)$. AMWs who reported adequate supervision were 5.04 times more likely to have higher knowledge of the critical danger signs compared with those who did not receive adequate supervision $(\mathrm{p}<0.001)$ (table 5$)$.

\section{Determinants of safe childbirth and immediate newborn care practices}

Multiple logistic regression reveals that having high knowledge of critical danger signs and reported adequate supervision were positively associated with practicing clean and safe childbirth and immediate newborn care (table 6). AMWs with high knowledge of the critical danger signs were 2.81 times more likely to practice safe childbirth and immediate newborn care compared with those who had low knowledge $(p=0.001)$. AMWs who reported that they had adequate supervision were 3.18 times more likely to practice safe childbirth and immediate newborn care compared with those who reported that they had no adequate supervision $(p=0.001)$. AMWs with above secondary level of education were $56 \%$ less likely to practice of safe childbirth and immediate newborn care practices compared with those without secondary level of education and below. $(\mathrm{p}=0.019)$.

\section{DISCUSSIONS}

The knowledge and practices of community health workers are important indicators of the quality of care provided by this cadre of health workers. The present study examined AMWs' knowledge of critical danger signs during pregnancy, childbirth, postpartum and the immediate newborn care period. Recognising critical danger signs is an essential prerequisite to timely referral of women and newborns to life-saving interventions. Our study revealed low knowledge of critical danger signs among AMWs in the study area. This finding is consistent with the findings of a previous study of AMWs' general knowledge including danger signs in four townships of Kyaukse, Myanmar ${ }^{13}$ and is concerning.
In the present study, AMWs with higher age ( $\geq 35$ years) were more than twice as likely to be knowledgeable about critical danger signs compared with the younger age group. However, age was not associated with practice of care. A similar study of female community health workers in rural Nepal also found that women who were older had better knowledge of maternal and child health services. ${ }^{18}$ Our findings suggest that knowledge comes with experience and that the training needs to be strengthen to ensure that those newly engaged in the AMW work are appropriately knowledgeable.

Level of formal education was not associated with AMW knowledge in our study, but was inversely associated with provision of practice of care. We found that AMWs with higher than secondary level of education were less likely to report safe childbirth and immediate newborn care practices than those with lower education levels. This could be due to the fact that AMWs with better education are more likely to be involved in other jobs with better financial incentives compared with those AMWs who are less educated. Similar findings have been reported by a previous study on AMW performance in Myanmar, which showed that high education level was negatively associated with good performance. ${ }^{19}$ Training is a major determinant of knowledge and practice by community health workers globally. ${ }^{20}$ In the present study, receiving refresher training within 1 year was strongly associated with knowledge of critical danger signs. As some of the AMWs in the study conduct deliveries rarely, and to maintain good knowledge refresher trainings are important. The apparent success of more recent training (which was based on the new AMW manual) suggests that refresher trainings need to be extended to all AMWs. However, the overall low level of knowledge, even among recently trained AMWs calls for improved AMW training and support relating to the identification of danger signs. In the current AMW manual, extensive information covering a wide range of health topics may result in insufficient emphasis being 
Table 5 Determinants of consistent high knowledge of critical danger signs among 262 enrolled auxiliary midwives (AMWs)

\begin{tabular}{|c|c|c|c|c|}
\hline Variables & $\begin{array}{l}\text { Proportion with consistent } \\
\text { high knowledge of critical } \\
\text { danger signs }(\%, n / N)\end{array}$ & $\begin{array}{l}\text { OR } \\
(95 \% \mathrm{Cl})\end{array}$ & $\begin{array}{l}\text { Adjusted OR } \\
(95 \% \mathrm{Cl})\end{array}$ & p Value \\
\hline \multicolumn{5}{|c|}{ Sociodemographic characteristics } \\
\hline \multicolumn{5}{|l|}{ Villages } \\
\hline Hard-to-reach & $13 / 48(27.1)$ & 1.00 & 1.00 & 0.84 \\
\hline$<35$ years & $53 / 174(30.5)$ & 1.00 & 1.00 & \multirow[t]{2}{*}{0.054} \\
\hline$\geq 35$ years & $36 / 88(40.9)$ & 1.58 (0.92 to 2.71$)$ & 2.19 (0.99 to 4.87$)$ & \\
\hline \multicolumn{5}{|l|}{ Education } \\
\hline Secondary and below & $35 / 109(32.1)$ & 1.00 & 1.00 & 0.76 \\
\hline Married & $47 / 130(36.2)$ & 1.21 (0.73 to 2.03$)$ & 1.06 (0.57 to 2.02$)$ & 0.84 \\
\hline \multicolumn{5}{|c|}{ Number of years working as an AMW } \\
\hline$<10$ years & $41 / 134(30.6)$ & 1.00 & 1.00 & \multirow[t]{2}{*}{0.27} \\
\hline$\geq 10$ years & $48 / 128(37.5)$ & 1.36 (0.81 to 2.28$)$ & $0.61(0.25$ to 1.46$)$ & \\
\hline \multicolumn{5}{|c|}{ Any other job apart from AMW work } \\
\hline AMW only & $52 / 148(35.1)$ & 1.00 & 1.00 & \multirow[t]{2}{*}{0.20} \\
\hline Additional job & $37 / 114(32.5)$ & 0.89 (0.53 to 1.49$)$ & 0.68 (0.39 to 1.21$)$ & \\
\hline \multicolumn{5}{|c|}{ Training and supervision characteristics } \\
\hline
\end{tabular}

Bold indicates satistical significance.

placed on the more important topics, such as danger signs. Information such as using a partograph to assess the progress of labour is included, despite only 1 out of 262 participants in our study reporting having ever used a partograph. In terms of the training, the right content and appropriate methodology that suits the trainees is an important factor to be taken into consideration. ${ }^{21}$ Therefore, curriculum for training AMWs needs to be revisited and revised to prioritise the most relevant and practical information needed by AMWs.

Supervision is recognised internationally and in Myanmar as important for maintaining or increasing the community health workers' performance and quality of care. Previous studies illustrate that both the frequency of visits and the satisfaction of supervisee are important elements of effective supervision. ${ }^{120} 22$ Our study findings show that supervision is a consistent determinant of both knowledge and practice. AMWs who reported adequate supervision were five times more likely to have higher knowledge on critical danger signs and three times more likely to provide safe childbirth and immediate newborn care practices. To accelerate effective supervision, mechanisms for frequent, quality supervision need to be incorporated into AMW training packages. Although many studies note that supervision is essential, AMWs supervision in Myanmar is low. ${ }^{11} 13$

A systematic review done by Hill et al in 2014 found that supportive supervision given by formal health workers motivates community health workers, while also building trust and confidence between the two workers. ${ }^{22}$ Similar opportunities to build trust and confidence exist in Myanmar as supervision of AMWs is largely conducted by midwives in the local rural health centre. Although our study was limited to supervision by the immediate supervising midwife, supervision by other level of healthcare workers and community members has been effective in other settings $^{22-24}$ and should be explored in the Myanmar context. 
Table 6 Determinants of safe childbirth and immediate new born care practices of 262 auxiliary midwives (AMWs) enrolled in the study

\begin{tabular}{|c|c|c|c|c|}
\hline Variables & $\begin{array}{l}\text { Proportion of AMWs with } \\
\text { all six practices of safe and } \\
\text { clean childbirth and new } \\
\text { born care practices }(n / N)\end{array}$ & $\begin{array}{l}\text { OR } \\
(95 \% \mathrm{Cl})\end{array}$ & $\begin{array}{l}\text { Adjusted OR } \\
(95 \% \mathrm{Cl})\end{array}$ & p Value \\
\hline \multicolumn{5}{|c|}{ Sociodemographic characteristics } \\
\hline \multicolumn{5}{|c|}{ Villages } \\
\hline Hard-to-reach & 10/48 (20.8) & 1.00 & 1.00 & \multirow[t]{2}{*}{0.67} \\
\hline Non-hard-to-reach & $64 / 214(29.9)$ & 1.62 (0.76 to 3.46$)$ & 1.20 (0.51 to 2.82$)$ & \\
\hline \multicolumn{5}{|l|}{ Age } \\
\hline$<35$ years & $47 / 174(27.0)$ & 1.00 & 1.00 & \multirow[t]{2}{*}{0.72} \\
\hline$\geq 35$ years & $27 / 88(30.7)$ & 1.20 (0.68 to 2.10$)$ & 1.16 (0.50 to 2.68$)$ & \\
\hline \multicolumn{5}{|l|}{ Education } \\
\hline Secondary and below & 38/109 (34.9) & 1.00 & 1.00 & \multirow[t]{2}{*}{0.019} \\
\hline Above secondary & $36 / 153(23.5)$ & 0.57 (0.33 to 0.99$)$ & $0.44(0.23$ to 0.88$)$ & \\
\hline \multicolumn{5}{|l|}{ Marital status } \\
\hline Single & $39 / 132(29.6)$ & 1.00 & 1.00 & \multirow[t]{2}{*}{0.24} \\
\hline Married & $35 / 130$ (26.9) & $0.88(0.51$ to 1.51$)$ & 0.66 (0.33 to 1.32$)$ & \\
\hline \multicolumn{5}{|c|}{ Number of years working as an AMW } \\
\hline$<10$ years & $34 / 134(25.4)$ & 1.00 & 1.00 & \multirow[t]{2}{*}{0.79} \\
\hline$\geq 10$ years & 40/128 (31.3) & 1.33 (0.78 to 2.30$)$ & 0.88 (0.35 to 2.24$)$ & \\
\hline \multicolumn{5}{|c|}{ Any other job apart from AMW work } \\
\hline AMW only & $36 / 148(24.3)$ & 1.00 & 1.00 & \multirow[t]{2}{*}{0.17} \\
\hline Additional job & 38/114 (33.3) & 1.56 (0.90 to 2.68$)$ & 1.53 (0.84 to 2.78$)$ & \\
\hline \multicolumn{5}{|c|}{ Training and supervision characteristics } \\
\hline \multicolumn{5}{|c|}{ Refresher training } \\
\hline No or 1 year and more & $33 / 125(26.4)$ & 1.00 & 1.00 & \multirow[t]{2}{*}{0.50} \\
\hline Less than 1 year & $41 / 137(29.9)$ & 1.19 (0.69 to 2.05$)$ & 1.25 (0.66 to 2.37$)$ & \\
\hline \multicolumn{5}{|l|}{ Adequate supervision } \\
\hline Not adequate & $17 / 124(13.7)$ & 1.00 & 1.00 & \multirow[t]{2}{*}{0.001} \\
\hline Adequate & $57 / 138(41.3)$ & 4.43 (2.32 to 8.45$)$ & $3.18(1.62$ to 6.24$)$ & \\
\hline \multicolumn{5}{|c|}{ Knowledge of critical danger signs } \\
\hline \multicolumn{5}{|c|}{ Consistent high knowledge of critical danger signs } \\
\hline No & $33 / 173(19.1)$ & 1.00 & 1.00 & \multirow[t]{2}{*}{0.001} \\
\hline Yes & $41 / 89(46.1)$ & $3.62(2.01$ to 6.52$)$ & $2.81(1.50$ to 5.26$)$ & \\
\hline
\end{tabular}

The 2006 Lancet series on maternal survival emphasised that the effectiveness of lay health workers programmes depend on comprehensive training, considerable supervision and logistical input, ${ }^{25}$ along with good planning. It is also well evident that community level health worker programmes are not stand-alone initiatives, and all effort within the health system must be involved to strengthen the knowledge and skills of AMWs who are the frontline workers of the hard-to-reach rural areas with innovative and effective training and supervision packages.

There are a number of limitations to the present study. Practices of AMWs were based on self-reported practices rather than actual observed performance, and over-reporting can be a problem with this approach. Our finding of low knowledge and poor practices may therefore still be an underestimate of the size of the problem. As a cross-sectional study, the study is not able to determine cause-effect relationships. Creating composite variables for analysis may impose misclassification bias and findings should be interpreted with caution. Despite these limitations, results revealed that adequate supervision and regular refresher trainings are strongly correlated with AMW knowledge and practice relating to safe childbirth practices and knowledge. These findings suggest that greater investment in training and supervision is warranted.

Myanmar, a country in transition, with a fragile and weak health system, has chosen the path of training 
AMWs in response to national shortages in human resources for health. This policy is in line with WHO's task-shifting recommendations that advocate for training and supporting lay health workers to perform specified tasks often performed by higher-level health cadres in order to improve access to care for hard-to-reach communities. ${ }^{8}$ However, our study finds that AMWs currently report low levels of knowledge regarding critical danger signs and poor practices relating to safe childbirth and immediate newborn care. Our findings underscore the need for comprehensive, skill-based training module with close supervision and support mechanism in order to improve the knowledge and skills of AMWs in Myanmar before future task shifting.

\section{Author affiliations}

${ }^{1}$ Burnet Institute, Melbourne, Australia

${ }^{2}$ Department of Medicine, Royal Melbourne Hospital, University of Melbourne, Melbourne, Australia

${ }^{3}$ Nossal Institute for Global Health, Melbourne School of Population and Global Health, Victoria, Australia

${ }^{4}$ Department of Epidemiology and Preventive Medicine and Central Clinical School, Faculty of Medicine Nursing and Health Science, Monash University, Melbourne, Australia

${ }^{5}$ Department of Obstetrics and Gynaecology, International Centre for Reproductive Health, Faculty of Medicine and Health Sciences, Ghent University, Ghent, Belgium

Acknowledgements The authors would like to acknowledge the Department of Public Health, Ministry of Health, Myanmar for the collaboration and all the administrative support given by the Magwe Regional Health Department and all the health staff in the three study townships. We are also grateful to Burnet Institute Myanmar research team members (Thazin La, Kyaw Soe Thant, Tin Tin Wai and Thandar Aye) for kindly assisting in data collection. We would also like to thank all the AMWs who participated in the study without whom this study would not have been possible.

Contributors KKT contributed to the study design, data collection, data analysis and led the first draft and finalisation of the manuscript. AM contributed to data analysis and development of the manuscript. MDP contributed to data analysis. JGB contributed to the study design and development of the manuscript. SL contributed to the study design, data analysis and led the revisions of the manuscript. All authors read and approved the final manuscript.

Funding The Burnet Institute is supported by funding from the Victorian Operational Infrastructure Support Program and National Health and Medical Research Council (NHMRC) Independent Research Institute Infrastructure Support Scheme. James G Beeson (JGB) and Stanley Luchters (SL) were supported by NHMRC fellowships. Kyu Kyu Than (KKT) was supported by an Australian Award Scholarship of the Australian Government. Minh Duc Pham (MDP) was supported by an International Postgraduate Research Scholarship (IPRS) from the Commonwealth of Australia and a Victorian International Research Scholarship (VIRS) from State Government of Victoria, Australia.

\section{Competing interests None declared.}

Patient consent Detail has been removed from this case description/these case descriptions to ensure anonymity. The editors and reviewers have seen the detailed information available and are satisfied that the information backs up the case the authors are making.

Ethics approval Ethical approval for the study was obtained from the Ethics Review Committee of Department of Medical Research, Ministry of Health Myanmar (approval number 42A/ethics/DMR/2015). Ethical approval was also obtained from The Alfred Hospital Human Research Ethics Committee in Australia (approval number Project 150/15). Written information was provided in Burmese and written inform consent was obtained

Provenance and peer review Not commissioned; externally peer reviewed.

Data sharing statement Data will be available on request as this is part of a larger study on "The role of auxiliary midwives in community-based maternal and child health care in Myanmar: an assessment of the feasibility of task shifting".
Open Access This is an Open Access article distributed in accordance with the Creative Commons Attribution Non Commercial (CC BY-NC 4.0) license, which permits others to distribute, remix, adapt, build upon this work non-commercially, and license their derivative works on different terms, provided the original work is properly cited and the use is non-commercial. See: http://creativecommons.org/ licenses/by-nc/4.0/

(c) Article author(s) (or their employer(s) unless otherwise stated in the text of the article) 2017. All rights reserved. No commercial use is permitted unless otherwise expressly granted.

\section{REFERENCES}

1. Perry HB, Zulliger R, Rogers MM. Community health workers in low-, middle-, and high-income countries: an overview of their history, recent evolution, and current effectiveness. Annu Rev Public Health 2014;35:399-421.

2. Lehmann U, Sanders D. Community health workers: what do we know about them. The state of the evidence on programmes, activities, costs and impact on health outcomes of using community health workers. Geneva: World Health Organization, 2007:1-42.

3. Witmer A, Seifer SD, Finocchio L, et al. Community health workers: integral members of the health care work force. Am J Public Health 1995:85:1055-8.

4. Department of Health - Ministry of Health Myanmar. Situational analysis on training and utilization of auxiliary midwives, 1985.

5. Department of Health - Ministry of Health Myanmar. Auxiliary midwife training manual (Myanmar Language. Department of Health, 2015.

6. Ministry of Health Myanmar. Health workforce strategic plan 2012-2017, 2012.

7. Department of Health, Ministry of Health Myanmar. Microplan for auxiliary midwives (2013-2016). Department of Health, 2013.

8. World Health Organization. WHO recommendations: optimizing health worker roles to improve access to key maternal and newborn health interventions through task shifting OPTIMINIZEMNH. Geneva, 2012.

9. Vogel JP, Moore JE, Timmings C, et al. Barriers, facilitators and priorities for implementation of WHO maternal and perinatal health guidelines in four lower-income countries: a GREAT network research activity. PLoS One 2016;11:e0160020.

10. The three millennium development goal fund. 2015 Annual report. 2016.

11. Burnet Institute Myanmar. Documenting the lessons learnt from the Joint Initiative on Maternal Neonatal \& Child Health (JIMNCH) Ayarwaddy Region, 2013.

12. Department of Health, Ministry of Health Myanmar. Assessment of performance and acceptablity of auxillary midwives in rural communities as a strategy to improve maternal health, 2005.

13. Department of Health, Ministry of Health Myanmar. Assessment of auxiliary midwives training and utilization in Kyaukse township, 2011.

14. Department of Population, Ministry of Labour Immigration and Population-The Republic of the Union of Myanmar. Thematic report on maternal mortality, census report volume 4-C, 2016.

15. Department of Population, Ministry of Labour Immigration and Population-The Republic of the Union of Myanmar. Thematic report on mortality, census report volume 4-B, 2016:1-115.

16. Ministry of Health and Sports (MoHS) and ICF. Myanmar demographic and health survey 2015-16. Nay Pyi Taw, Myanmar, and Rockville, Maryland USA, 2017.

17. The Three Millennium Development Goal Fund. 3MDG maternal and newborn and child health indicator guidelines, 2013.

18. Acharya D, Singh JK, Adhikari S, et al. Association between sociodemographic characteristics of female community health volunteers and their knowledge and performance on maternal and child health services in rural Nepal. J Multidiscip Healthc 2016;9:111-20.

19. TH Min , WM Oo, AA Oo. Factors influencing the involvement of Auxiliary Midwives in health service provision in Salin Township . Myanmar Med J 2015;57:19-26.

20. World Health Organization. 2006. World Health Report 2006: Working Together for Health, WHO, Geneva.

21. Rakhshani F, Mohammadi M. Improving community health workers' knowledge and behaviour about proper content in malaria education. $J$ Pak Med Assoc 2009;59:395.

22. Hill $Z$, Dumbaugh $M$, Benton $L$, et al. Supervising community health workers in low-income countries - a review of impact and implementation issues. Glob Health Action 2014;7:24085.

23. Gilmore B, McAuliffe E. Effectiveness of community health workers delivering preventive interventions for maternal and child health in 
low- and middle-income countries: a systematic review. BMC Public Health 2013;13:847.

24. Haver J, Brieger W, Zoungrana J, et al. Experiences engaging community health workers to provide maternal and newborn health services: implementation of four programs. Int J Gynaecol Obstet 2015;130 Suppl 2:S32-S39.

25. Campbell OM, Graham WJ. Lancet Maternal Survival Series steering group. Strategies for reducing maternal mortality: getting on with what works. Lancet 2006;368:1284-99. 